Check for updates

Cite this: J. Mater. Chem. C, 2020 8, 14499

Received 29th July 2020, Accepted 30th September 2020

DOI: $10.1039 / \mathrm{dOtc03597a}$

rsc.li/materials-c

\section{Mixed-ligand zinc-oxoclusters: efficient chemistry for high resolution nanolithography $\dagger$}

\author{
Neha Thakur, (D) *a Roland Bliem, (D) a lacopo Mochi, ${ }^{\text {b }}$ Michaela Vockenhuber, ${ }^{b}$ \\ Yasin Ekinci (D) ${ }^{b}$ and Sonia Castellanos (D) *a
}

\begin{abstract}
Extreme ultraviolet lithography (EUVL) is the current technology used in the semiconductor industry for the fabrication of integrated circuits (ICS), since it enables the further miniaturization of their components. For its optimal operation, photoresist materials that can efficiently use EUV photons (92 eV) to yield sub-10 nm patterns are required. However, there is a lack of understanding of the complex mechanisms induced by EUV radiation. In this work, we investigate the ability of a new $\mathrm{Zn}$-based oxocluster to fulfil the state-of-the-art requirements for EUVL. This molecular material was conceived to provide high EUV absorptivity, owing to its contents of Zn, F, and O atoms, and high resolution, given its small molecular size. High sensitivity/reactivity towards EUV is achieved through its mixed-ligand organic shell composed of methacrylate and trifluoroacetate ligands. This new resist shows outstanding lithography performance yielding down to $22 \mathrm{~nm}$ half pitch line/space patterns at

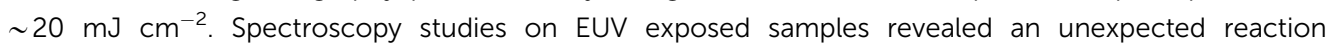
pathway where fluoride ions are formed. This is an unprecedented way of efficiently inducing a solubility switch in an inorganic resist upon EUV irradiation.
\end{abstract}

\section{Introduction}

The downscaling of ICs in computer chips and memory devices over the years has been possible thanks to advances in lithography techniques. ${ }^{1-3}$ Among them, photolithography has been the workhorse of the semiconductor industry for ICs fabrication. In this technique, an optical projection is captured by a sacrificial photoactive layer, known as photoresist, so that the optical pattern can be transferred to the functional substrate that is the integrating part of the ICs. Within the next five years, the projected device feature size should be less than 10 nanometres. ${ }^{4,5}$ For such miniaturization to be cost-effective, the semiconductor industry shifted from deep ultraviolet (DUV) photolithography, using light of $193 \mathrm{~nm}$, to the next-generation technique, extreme ultraviolet lithography (EUVL), as its shorter wavelength $(13.5 \mathrm{~nm})$ offers higher resolution. ${ }^{1,6}$

EUV photons exceed the ionization energy of any resist material so that EUV irradiation leads to complex mechanisms that involve the generation of photoelectrons and secondary electrons, together with the associated holes (electron vacancies). ${ }^{7-9}$ The understanding of this complex EUV-induced chemistry is

\footnotetext{
${ }^{a}$ Advanced Research Center for Nanolithography, Science Park 106, Amsterdam 1098XG, The Netherlands.E-mail: n.thakur@arcnl.nl, s.castellanos@arcnl.nl

${ }^{b}$ Paul Scherrer Institute, Forschungstrasse 111, Villigen 5232, Switzerland

$\dagger$ Electronic supplementary information (ESI) available. See DOI: 10.1039/ d0tc03597a
}

currently rather limited. ${ }^{10,11}$ Yet, without the proper EUVchemistry knowledge, it is a challenge to custom-design materials for EUVL that can meet the industrial targets of sensitivity $\left(<20 \mathrm{~mJ} \mathrm{~cm}^{-2}\right)$, low line width/line edge roughness (LWR/LER $<20 \%$ ), and resolution $(<20 \mathrm{~nm}) .{ }^{4,11-13}$

A prerequisite for EUV resist materials is high absorbance at $13.5 \mathrm{~nm} .{ }^{14,15}$ A straightforward approach to attain this is to incorporate elements into the resist layer that have high EUV absorption cross-section, typically metals. Such materials are commonly called inorganic resists and have emerged as promising candidates for EUVL applications. ${ }^{15-17}$ In addition to the enhancement of EUV photon absorption, inorganic resists are also known to overcome the low tolerance of traditional organic polymers towards the etching conditions. ${ }^{18}$ In most cases, inorganic resists comprise a core of one or more metal cations surrounded by organic ligands. ${ }^{8,15,16}$ Exposure to the EUV photons (and the electron cascade that derive from them) induce chemical reactions on the organic ligands that result in the change of solubility properties of the resist material in the exposed areas, which ultimately leads to the pattern formation on resist layers. ${ }^{19-25}$

Metal-oxoclusters (MOCs) stand out among EUV inorganic resists since they are molecularly defined (small and homogeneous in size) and therefore, are anticipated to prevent variations in the nanopatterns, i.e. low LWR/LER values in the printed features. ${ }^{26-29}$ In addition, MOCs provide great synthetic flexibility, since virtually any desired organic terminal functionality can be 
incorporated in their organic shell, allowing for an easy way of tuning the processability and chemical reactivity of the material. ${ }^{25,30,31}$

In the present work, we investigate the lithographic capabilities of a Zn-based MOC and study the EUV-induced chemistry that enables nanopatterning on this material. This MOC consists of a tetranuclear $\mathrm{Zn}$-compound that belongs to the group of basic zinc carboxylates ${ }^{32-34}$ and is found in the nodes of a prototypical metal-organic framework, MOF-5. ${ }^{35-37}$ Previously, dinuclear Zn-complexes proved to work as EUV resists. ${ }^{26}$ Here, we aimed at enhancing the EUV absorbance thanks to the more condensed $\mathrm{Zn}$-based oxo core and to the integration of fluorine atoms ${ }^{38}$ as part of trifluoroacetate ligands (TFA) in the organic shell. Moreover, we incorporated methacrylate ligands (MA), which can undergo cross-linking upon EUV irradiation. ${ }^{24,30}$

This reaction is in fact common in MA-based clusters when irradiated with lower energy (UV) light sources, ${ }^{39-42}$ and we anticipated that it would contribute to the solubility switch in this new Zn-based material. These considerations gave rise to a Zn-oxocluster shown in Fig. 1a and labelled as Zn(MA)(TFA). This molecular material is a mixture of clusters with an average composition of $\mathrm{Zn}_{4} \mathrm{O}(\mathrm{MA})_{5}(\mathrm{TFA})$. This compound has previously shown to have a high linear absorption coefficient at $13.5 \mathrm{~nm}\left(12.4 \mu^{-1}\right)$ and high sensitivity. ${ }^{43}$ Here, we used EUV interference lithography (EUV-IL) ${ }^{44,45}$ to achieve dense line/space (L/S) patterns of half-pitch (HP) down to $22 \mathrm{~nm}$ at low doses $\left(\sim 20 \mathrm{~mJ} \mathrm{~cm}^{-2}\right)$ on this material, a response that is close to commercial EUV resists. ${ }^{12,13,17}$ The lithography experiments were also combined with several ex situ spectroscopic techniques, which allowed to elucidate a novel mechanism behind the nanopattern formation involving $\mathrm{C}-\mathrm{F}$ bond cleavage in the TFA ligands and cross-linking of the double bond of MA ligands initiated by different radical species (Scheme 1).

\section{Experimental section}

\subsection{Synthesis of $\mathrm{Zn}(\mathrm{MA})(\mathrm{TFA})$ and thin film deposition}

The $\mathrm{Zn}$ (MA)(TFA) compound was synthesized by ligand exchange from a commercial Zn-oxocluster as precursor having the same tetranuclear oxo-core unit and six TFA ligands, $\mathrm{Zn}_{4} \mathrm{O}\left(\mathrm{OOCCF}_{3}\right)_{6}$, following the protocol in ref. 43 and as shown in Fig. 1a. The deposition of thin films was performed from a $\mathrm{Zn}$ (MA)(TFA) solution of $2 \%(\mathrm{w} / \mathrm{v})$ in a mixture of chloroform $\left(\mathrm{CHCl}_{3}\right)$, and propylene glycol methyl ether acetate (PGMEA), 9:1 v/v followed by sonication (4 min) and filtration using a $0.22 \mu \mathrm{m}$ PTFE filter. Spin-coating of the resist solution was done at $2100 \mathrm{rpm}$ spinning speed (acceleration $3000 \mathrm{rpm} \mathrm{s}^{-1}$ ) for $30 \mathrm{~s}$. Post application baking was applied for $30 \mathrm{~s}$ at $90{ }^{\circ} \mathrm{C}$ to remove the excess of the residual solvent. Samples for UV-vis absorption spectroscopy were spin-coated on quartz substrates (500 $\mu \mathrm{m}$ thick) and for FTIR spectroscopy on double-side polished Si substrates (200 $\mu \mathrm{m}$ thick). Samples for X-ray photoelectron spectroscopy (XPS) analysis were spin coated on $\mathrm{Cr} / \mathrm{Au}$ (3 nm/19 nm) sputter-coated on Si substrate. The thickness of the thin films spin coated for spectroscopic analysis was in the range of 25-30 $\mathrm{nm}$ and was measured by using AFM.

\subsection{EUV exposure and development}

All EUV exposures were carried out at a wavelength of $13.5 \mathrm{~nm}$ (92 eV), at XIL-II beamline of the Swiss Light Source (SLS) synchrotron. For spectroscopic studies open frame $1.7 \times$ $1.7 \mathrm{~mm}^{2}$ area mask and pin-hole (PI), $70 \mu \mathrm{m}$ was used. For L/S features, the EUVL-IL ${ }^{44}$ tool was equipped with a transmission mask that resolved half-pitch (HP) of 22, 30, 40, and $50 \mathrm{~nm}$ combined with a PI $70 \mu \mathrm{m}$. Diluted propionic acid $(0.05 \%)$ in $\mathrm{CHCl}_{3}$ was used as a developer (8-10 s). $\mathrm{Zn}(\mathrm{MA})(\mathrm{TFA})$ behaved as a negative tone photoresist and therefore the exposed areas

(a)
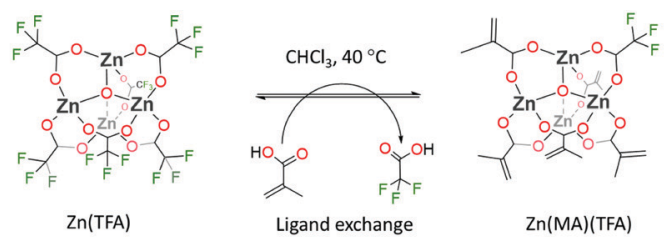

(b)

(c)
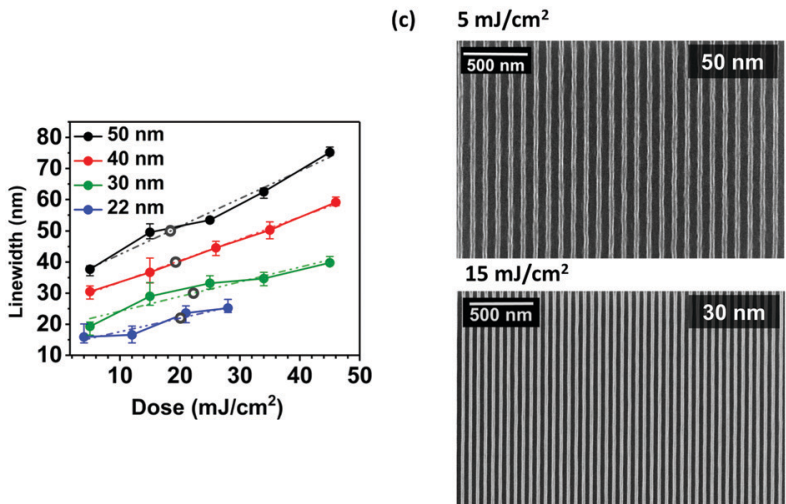

$5 \mathrm{~mJ} / \mathrm{cm}^{2}$

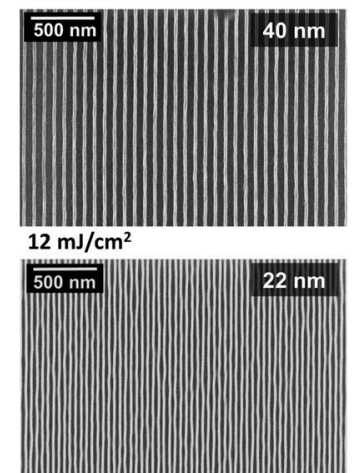

Fig. 1 (a) Scheme of Zn(MA)(TFA) synthesis. (b) Dose dependence of line-width of line/space patterns of different half-pitch measured with SEM (2 kV), where grey hollow dots represent the dose-to-size. (c) Selected SEM (5 kV) images of patterned line/space features using EUV-IL. 


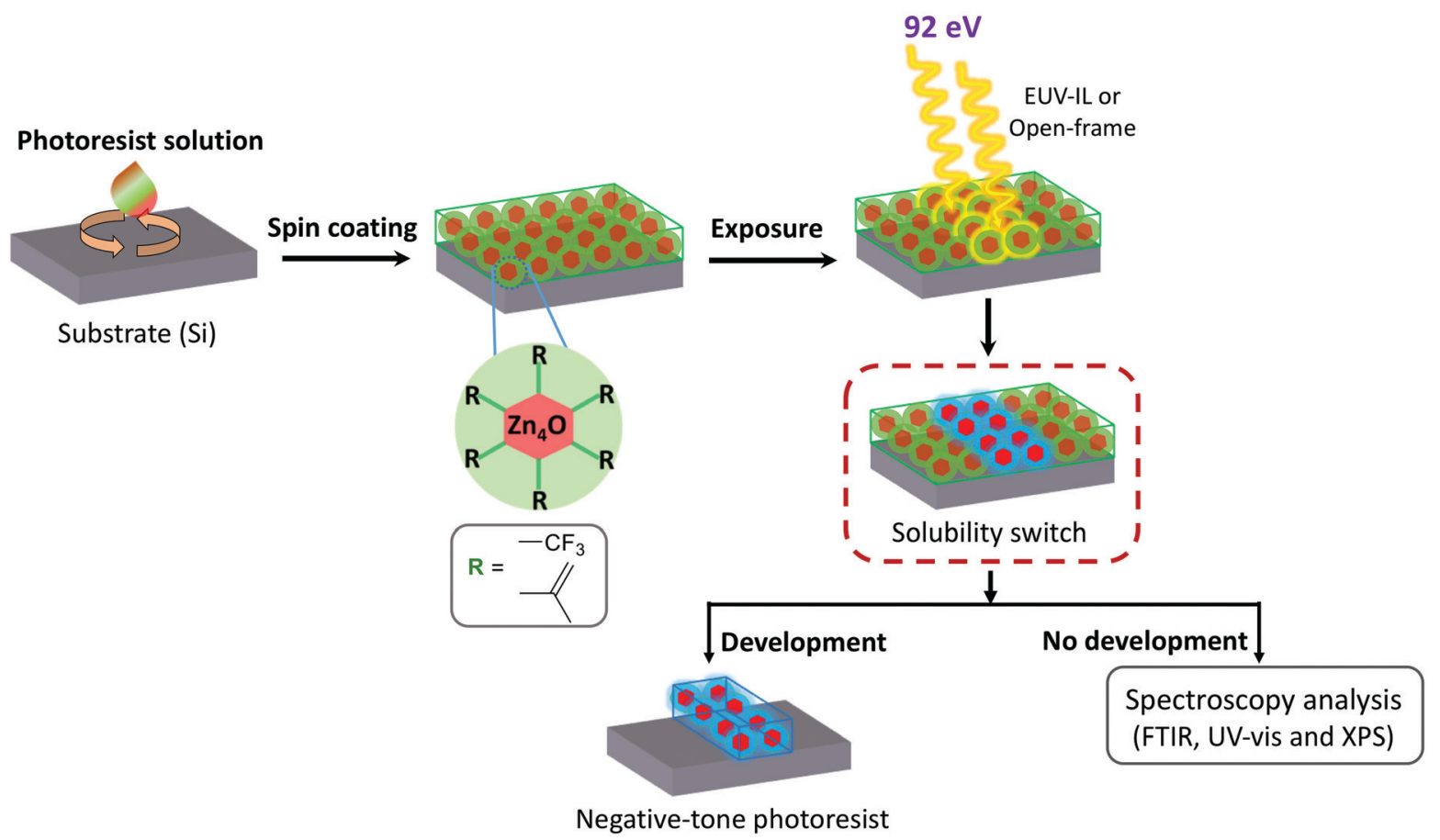

Scheme 1 Photolithography process and sample fabrication for ex situ spectroscopic analysis performed on Zn(MA)(TFA).

turn insoluble in the chosen developer. All the mentioned doses in this work are specific to this EUV-IL setup. The tool factors for the specific mask and PI combinations are calculated by crosscalibration with a bench-mark resist material. Thus, this might not correspond to an absolute number and doses might differ slightly when using a different EUV exposure tool. ${ }^{17}$

\subsection{Post-exposure analysis}

UV-vis absorption spectroscopy was performed in a Shimadzu UV2600 spectrophotometer. FTIR spectroscopy of the thin films was performed in transmission mode under vacuum in a Bruker Vertex 80v spectrometer. XPS was performed using a monochromatic $\mathrm{AlK}_{\alpha}$ source $(1486.6 \mathrm{eV})$ in an ultra-high vacuum setup ( $p \leq 5 \times 10^{-9}$ mbar) equipped with Scienta R4000 HiPP-3 analyser. Fitting of the peaks was done using UNIFIT 2018 Scientific software. SEM imaging on L/S features was performed with a top-down view using a FEI Verios 460 operating at a current of $100 \mathrm{pA}$, dwell time of $10 \mu \mathrm{s}$ and altering voltage of $5 \mathrm{kV}$ and $2 \mathrm{kV}$. LWR evaluation was carried out using SMILE, a SEM image analysis software developed at the Paul Scherrer Institute. Unbiased LWRs values ${ }^{46}$ were obtained using the average power spectral density (PSD) of the lines in their respective SEM images, the unbiasing was performed using a standard PSD model. ${ }^{47}$ AFM measurements were done using a Bruker Dimensions Icon in ScanAsyst-air mode. As a control experiment, a spectrum of a freshly spincoated thin film was also used (fresh reference) to inspect the effect of aging/partial degradation of the sample occurring between the exposure and the spectroscopy experiments (as shown in ESI $\dagger$ ).

\section{Results and discussion}

To evaluate $\mathrm{Zn}(\mathrm{MA})(\mathrm{TFA})$ as a photoresist for EUV lithography, dense L/S patterns on the thin film $(22-50 \mathrm{~nm})$ were printed using the EUV-IL tool at the Paul Scherrer Institute. ${ }^{48}$ SEM images (Fig. 1c) show that the transfer of L/S patterns needed a notably low dose. No scumming (scattered rests of material) between lines was observed. An important aspect in a resist performance is the dose-to-size, which is the incident exposure dose that is needed to attain features of the intended dimension. The plot of printed linewidth as a function of dose for $\mathrm{Zn}$ (MA)(TFA) (Fig. 1b) ${ }^{49}$ showed that the dose-to-size (hollow dots) in all cases is close to $20 \mathrm{~mJ} \mathrm{~cm}^{-2}$, which is the current requirement for EUV resists. The aspect ratio of the $\mathrm{L} / \mathrm{S}$ patterns were estimated using the height as measured from the corresponding AFM contour profiles (shown in ESI, $\uparrow$ Fig. S1) and found to be $\sim 1: 3$ for $\mathrm{HP} 50 \mathrm{~nm}, 30 \mathrm{~nm}$, and $22 \mathrm{~nm}$, and $\sim 1: 2$ for HP $40 \mathrm{~nm}$. The unbiased LWRs (shown in Fig. 2) of dense $\mathrm{L} / \mathrm{S}$ features were calculated for the doses of HPs nearest to the printed dose-to-size values (as shown above in Fig. 1b). As a result of line wiggles seen in SEM image of HP $22 \mathrm{~nm}$ the results of unbiased LWR are relatively higher. However, the LWR values of the other HP fulfil the industry requirement (LWR $<20 \%$ of CD). ${ }^{12}$ It should be noticed that a good control in the $\mathrm{Zn}$ (MA)(TFA) composition is crucial for reproducibility in the sensitivity of this resist. ${ }^{43}$ Table 1 below summarises the performance of some inorganic and hybrid inorganic-organic EUV photoresist when exposed using the EUVL-IL tool at PSI.

The promising outstanding performance of this new material prompted us to investigate the underlying mechanism in the pattern formation. In particular, we wanted to gain insight in 

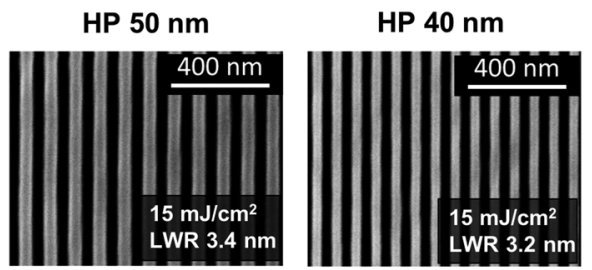

HP $30 \mathrm{~nm}$
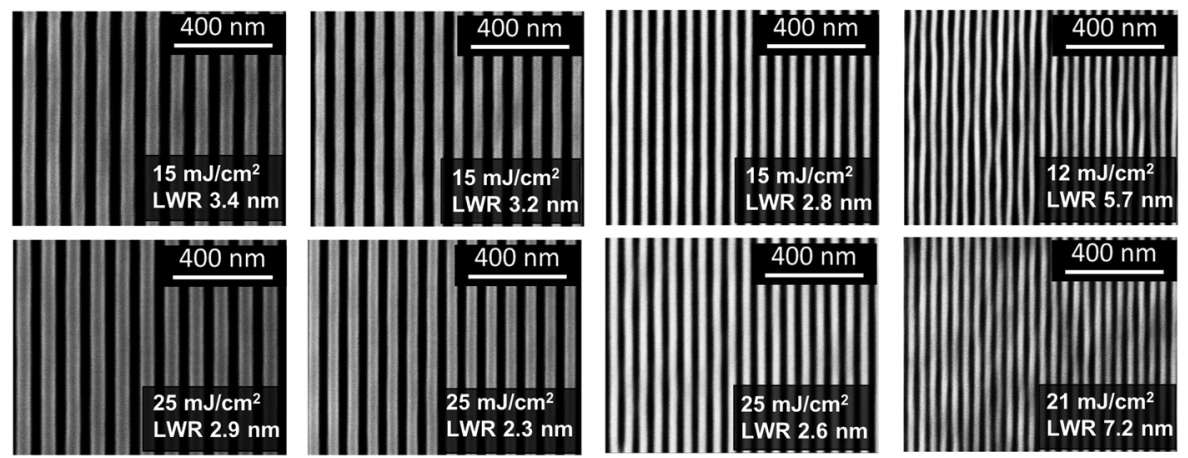

Fig. 2 LWR (unbiased) results obtained from PSD of respective SEM (operated at $2 \mathrm{kV}$ ) images of line/space features.

Table 1 Performance of some inorganic/hybrid inorganic-organic EUV photoresists tested with the EUV-IL tool at PSI grouped by their content of metallic element

\begin{tabular}{lllll}
\hline Resist & $\begin{array}{l}\mathrm{CD}[\mathrm{HP}] \\
(\mathrm{nm})\end{array}$ & $\begin{array}{l}\text { Dose } \\
\left(\mathrm{mJ} \mathrm{cm}^{-2}\right)\end{array}$ & $\begin{array}{l}\text { LWR/LER } \\
(\mathrm{nm})\end{array}$ & Ref. \\
\hline Inpria YA-BA & $14.9[16]$ & 48 & 1.8 & 50 \\
& $10[11]$ & - & 1.7 & \\
{$\left[(\mathrm{PhSn})_{12} \mathrm{O}_{14}(\mathrm{OH})_{6}\right] \mathrm{Cl}_{2}$} & {$[18]$} & 350 & - & 51 \\
{$\left[(\mathrm{BuSn})_{12} \mathrm{O}_{14}(\mathrm{OH})_{6}\right](\mathrm{OH})_{2}$} & {$[50]$} & 131 & - & 52 \\
{$\left[(\mathrm{BuSn})_{12} \mathrm{O}_{14}(\mathrm{OH})_{6}\right](\mathrm{AcO})_{2}$} & {$[40]$} & 74 & - & 52 \\
$\mathrm{HSQ}$ & {$[22]$} & $40-90$ & $\sim 2-3$ & 53 \\
$\mathrm{Zr}_{6} \mathrm{O}_{4}(\mathrm{OH})_{4} \mathrm{Mc}_{12}$ & {$[50]$} & 57 & - & 30 \\
$\mathrm{Zn}_{2}\left(\mathrm{CO}_{2} \mathrm{R}\right)_{4} \mathrm{Zn}-\mathrm{mTA}$ & {$[16]$} & 45 & - & 26 \\
& {$[13]$} & 35 & - & \\
$\mathrm{Zn}(\mathrm{MA})(\mathrm{TFA})$ & 30 & 22 & $2.8-2.6$ & \\
& 22 & 20 & $5.7-7.2$ &
\end{tabular}

the role of each type of ligand in the solubility switch that it undergoes after EUV irradiation. For that purpose, the chemical changes after EUV exposure were investigated with different ex situ spectroscopic techniques. FTIR and UV-vis absorption spectroscopy were employed to identify modifications in the organic ligands, whereas XPS allowed to detect changes in both inorganic and organic components, as it gives information on elemental ratio and on the chemical environment of all elements.

Thin films were exposed to four doses of EUV light from a dose above the threshold necessary to render a fully insoluble thin film $\left(>20 \mathrm{~mJ} \mathrm{~cm}^{-2}\right)^{43}$ up to a high dose where a full conversion of the pristine materials is expected, thus allowing the identification of the spectral features from the EUV irradiation product in $\mathrm{Zn}(\mathrm{MA})(\mathrm{TFA})$ resist.

A thin film of $\mathrm{Zn}$ (MA)(TFA) on Si was exposed to increasing EUV doses on different areas (Fig. 3b) of the same sample and the FTIR of each area was collected (Fig. 3a). The peaks were assigned according to the literature of $\mathrm{Zn}$-based tetranuclear clusters. ${ }^{36,43,54} \mathrm{~A}$ decrease in the area of the peaks (Fig. 3c) assigned to the carboxylate groups of both ligands, TFA $\left(\nu_{\text {as }} 1676 \mathrm{~cm}^{-1}\right)$ and MA $\left(\nu_{\text {as }} 1544 \mathrm{~cm}^{-1}\right)$, was detected with increasing dose. The same trend was observed for the peaks assigned to $\mathrm{C}-\mathrm{F}$ stretching (1205 and $1155 \mathrm{~cm}^{-1}$ ). However, a relative increase of the peaks in the aliphatic $\mathrm{C}-\mathrm{H}$ stretching region (2929-2885 $\left.\mathrm{cm}^{-1}\right)$ was observed. This indicates that EUV
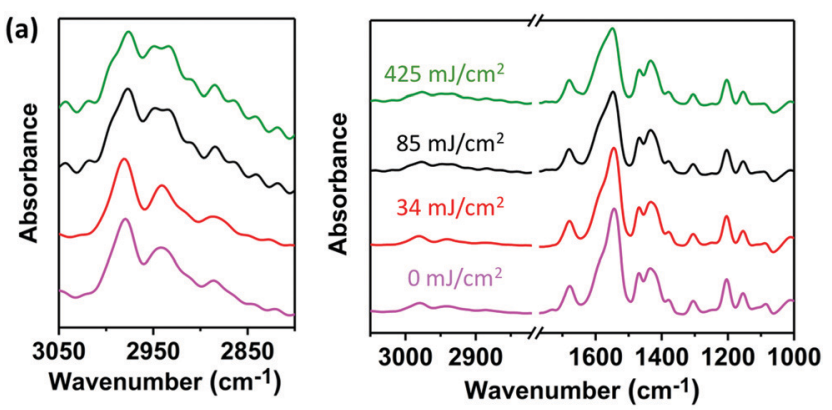

(b)

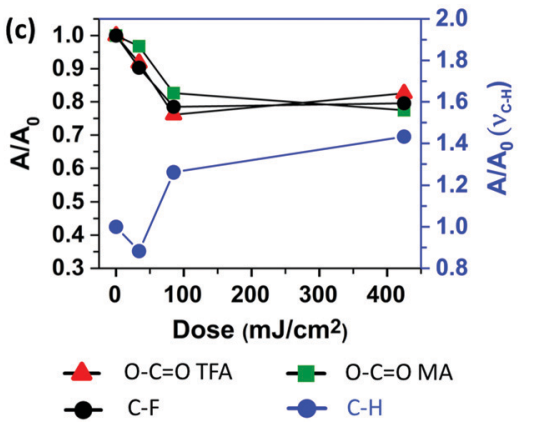

Fig. 3 (a) FTIR spectra of a Zn(MA)(TFA) resist film before and after EUV exposure. (b) Scheme of an exposed sample where delimited areas were

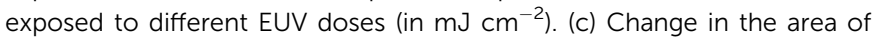
peaks related to MA and TFA ligands as a function of dose relative to the unexposed region.

photons promote the decarboxylation of both TFA and MA. In addition, the simultaneous decrease of the $\nu_{\text {as }}(\mathrm{COO})$ and $\nu(\mathrm{C}-\mathrm{F})$ peaks suggests that TFA ligands are partially lost, either as complete units or as a result of the ligand fragmentation arising from a decarboxylation process. However, in the case of the MA ligands, the preservation and increase of aliphatic $\mathrm{C}-\mathrm{H}$ stretching peaks is in line with cross-linking reactions between terminal double bonds.

To further investigate the reactivity of the MA ligands upon EUV exposure we monitored the changes in the UV-vis absorption spectrum of the material after irradiation with different doses of EUV light (Fig. 4). The unexposed material displays an absorption band at $198 \mathrm{~nm}$, which arises from electronic $\Pi \rightarrow \Pi^{*}$ transition localized in the MA ligands of 

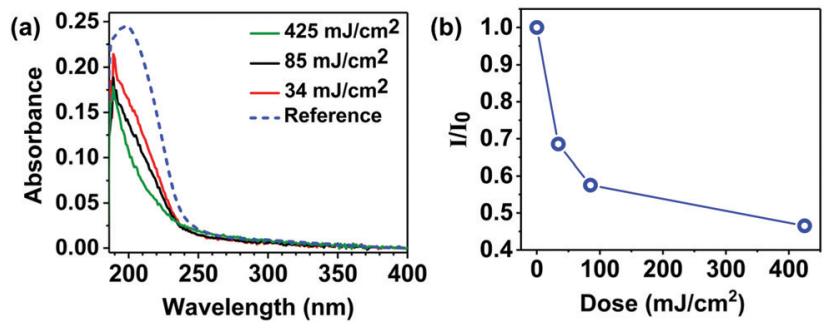

Fig. 4 (a) UV-vis absorption spectra of the resist film and (b) change in the UV-vis absorbance maximum relative to the reference as a function of EUV dose.

Zn(MA)(TFA) (Fig. 4a). The bleaching of this band as the EUV dose increases clearly indicates the loss of double bonds with EUV exposure (Fig. 4b). Taking into account that the FTIR experiments confirmed the presence and slight increase of $\mathrm{C}-\mathrm{H}$ bonds in aliphatic carbons, this result is in line with the promotion of cross-linking reactions between terminal double bonds, which yields saturated carbon chains..$^{24,30}$

As vibrational modes and electronic transitions arising from the inorganic core fall out of the spectroscopic windows in both FTIR and UV-vis experiments, XPS was used to investigate other processes that might occur in the Zn(MA)(TFA) molecule after EUV irradiation. We focused on the detection and tracking of different $\mathrm{C}, \mathrm{O}, \mathrm{F}$, and $\mathrm{Zn}$-species as the EUV exposure dose increased. To do so, we fitted the C 1s, O 1s, F 1s, and Zn 2 $\mathrm{p}_{3 / 2}$ high resolution spectra for the unexposed material and tracked the species of interest as a function of dose (Fig. 5a and Fig. S5 in ESI ${ }^{\dagger}$.

Although the C 1s spectra could be fitted with 4 components, here we will only consider the components with higher oxidation states, assigned to $\mathrm{C}$ atoms in the $\mathrm{O}-\mathrm{C}=\mathrm{O}$ groups $(289.1 \mathrm{eV})$ and $\mathrm{C}$ atoms bonded to F, C-F $(292.8 \mathrm{eV})$. O 1s spectra were fitted using 2 components, which we attribute to $\mathrm{O}$

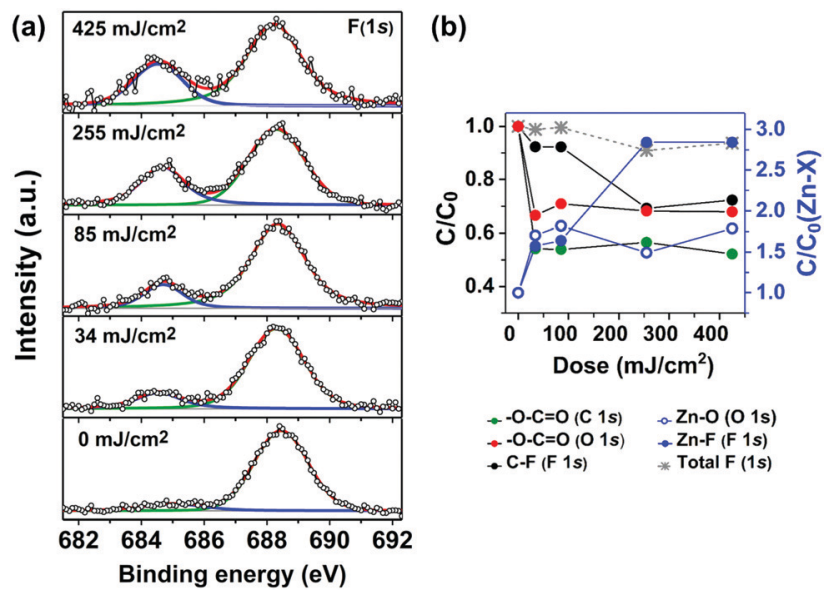

Fig. 5 (a) Experimental data (dots) and fitting (solid line) of the $F$ 1s highresolution spectra for unexposed and EUV exposed $Z n(M A)(T F A)$ resist. (b) Changes in the elemental ratio of components of $\mathrm{O}-\mathrm{C}=\mathrm{O}$ ( $C$ 1s), $\mathrm{O}-\mathrm{C}=\mathrm{O}(\mathrm{O} 1 \mathrm{~s})$ and $\mathrm{Zn}-\mathrm{O}(\mathrm{O} 1 \mathrm{~s}) \mathrm{C}-\mathrm{F}(\mathrm{F} 1 \mathrm{~s}), \mathrm{Zn}-\mathrm{F}(\mathrm{F} 1 \mathrm{~s})$ and in the total $\mathrm{F}$ ratio ( $F 1 s$ ) relative to $Z n$ as a function of EUV dose. atoms participating in $\mathrm{Zn}-\mathrm{O}$ bonds (oxo and hydroxo groups, $532.1 \mathrm{eV}$ ) and $\mathrm{O}$ atoms in $\mathrm{O}-\mathrm{C}=\mathrm{O}$ groups $(530.4 \mathrm{eV})$. A peak assigned to $\mathrm{F}$ atoms in the TFA ligands was found in the F 1s accompanied by a small peak with smaller chemical shift (see explanations below). The $\mathrm{Zn} 2 \mathrm{p}_{3 / 2}$ peak was fitted using only one component indicating no major chemical differences between the $\mathrm{Zn}$ atoms in the inorganic core (see ESI $\dagger$ ).

The evolution of the $\mathrm{C} 1 \mathrm{~s}$ and $\mathrm{O} 1 \mathrm{~s}$ high resolution spectra signified the loss of $\mathrm{O}-\mathrm{C}=\mathrm{O}$ species upon EUV exposure (Fig. S5, ESI $\dagger$ ), in line with the FTIR results. Yet the most prominent changes were observed in the high-resolution spectra of the F 1s (Fig. 5a). In the latter, it was noticed that the peak at $684.5 \mathrm{eV}$ increases as a function of EUV dose. This peak is assigned to fluoride ions, likely bonded to $\mathrm{Zn}$ metal (Zn-F) in the thin film after EUV exposure. ${ }^{55-57}$ The formation of such metal-fluoride bond has been observed in metal complexes after exposure to focused electron beam and was explained by $\mathrm{C}-\mathrm{F}$ bond cleavage and appearance of $\mathrm{F}^{-}$species. ${ }^{58}$ The presence of this peak in low intensity in the unexposed sample is attributed to the chemical changes induced by X-ray photons used for the XPS measurement, as a rise of this peak was observed as a result of prolonged irradiation with X-ray after consecutive measurements on the same spot (Fig. S5, ESI $\dagger$ ).

Since our X-ray photoelectron spectrometer does not have spatial resolution, for this experiment each dose required the preparation and exposure of a different sample. Therefore, to track the effect of EUV, we calculated the ratio of each species relative to $\mathrm{Zn}$ for each sample and the ratio found at each dose was compared to the initial ratio of each species in the unexposed sample. The ratios relative to $\mathrm{Zn} 2 \mathrm{p}_{3 / 2}$ of selected components in $\mathrm{C}$ 1s $(\mathrm{O}-\mathrm{C}=\mathrm{O}), \mathrm{O} 1 \mathrm{~s}(\mathrm{O}-\mathrm{C}=\mathrm{O}$ and $\mathrm{Zn}-\mathrm{O})$ and $\mathrm{F}$ 1s (C-F and $\mathrm{Zn}-\mathrm{F})$ spectra were plotted as a function of dose (Fig. 5b). Loss of carboxylate ( $\mathrm{O}-\mathrm{C}=\mathrm{O}, \mathrm{C} 1 \mathrm{~s}$ and $\mathrm{O} 1 \mathrm{~s})$ was detected, yet the contribution of TFA and MA to it cannot be distinguished with this technique, as both carboxylate peaks have the same chemical shift. An increase in $\mathrm{Zn}-\mathrm{O}$ component as a function of dose was also observed, which can be attributed to the formation of $\mathrm{ZnO}_{x}$ species after the EUV exposure. That is, after decarboxylation/ligand loss during exposure, the $\mathrm{Zn}$ atoms left in the film can react with water and oxygen in the atmosphere after the samples are taken out of the exposure chamber in the air. As the Zn-F species increase with EUV dose, a decrease in the C-F components is observed, simultaneously. The total concentration of fluorine (grey asterisks in Fig. 5b), decreased by $10 \%$ at high EUV doses. Overall, the changes detected in XPS in the fractional ratio with EUV exposure are fairly comparable to the results obtained from FTIR regarding decarboxylation and C-F bond loss.

From the combination of all spectroscopic results, we propose the reactions in Scheme 2 as important contributions to the solubility switch in the Zn(MA)(TFA) resist upon EUV exposure. Ionization of the oxoclusters after absorption of EUV radiation results in the emission of a photoelectron and formation of a radical cation that can further yield the decarboxylation of any of the two types of ligands (reaction (i) in Scheme 2). This process can also be initiated by an electron 

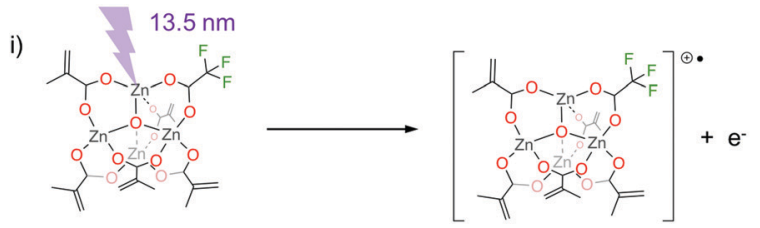

ii)
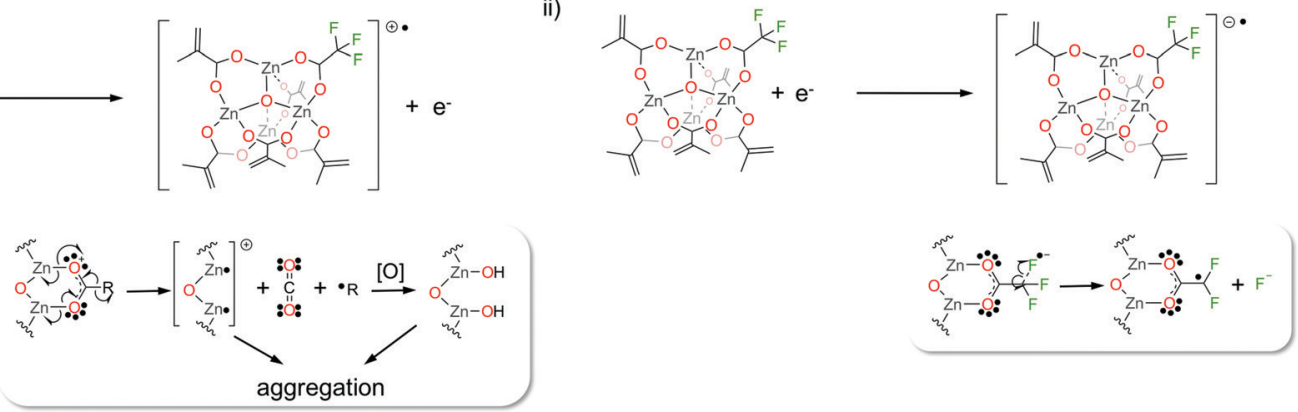

iii)

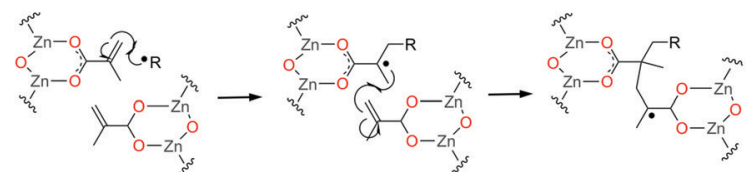

Scheme 2 Proposed reaction paths that contribute to the solubility switch in Zn(MA)(TFA) EUV resist.

with kinetic energy higher than the ionization potential of the molecule. ${ }^{59-61}$ The resulting fragments would be an allyl or a trifluoromethyl radical and an outgassing neutral $\mathrm{CO}_{2}$ molecule. These sites are likely to react with water or oxygen when the film is exposed to ambient atmosphere after EUV exposure and can further lead to aggregation with neighbouring clusters. ${ }^{62-64}$ Meanwhile, the radicals formed in path (i) can initiate cross-linking reactions of the terminal double bonds in the MA ligands (process (iii) in Scheme 2).

In addition to dissociative ionization processes, electrons with lower energy than the ionization potential can react with $\mathrm{Zn}(\mathrm{MA})(\mathrm{TFA})$ oxocluster and induce the C-F cleavage. This process, known as dissociative electron attachment (DEA), has been reported for halogen-containing molecules and in particular for trifluoroacetic acid. ${ }^{65-69}$ The resultant fragments would be $\mathrm{F}^{-}$and a difluoroacetyl radical (process (ii) in Scheme 2). Although a detailed structure of the final product cannot be inferred, XPS studies have clearly shown the presence of new $\mathrm{F}^{-}$species in the thin film after EUV exposure. We assume that they are stabilized by the $\mathrm{Zn}^{2+}$ metal cations, as explained above. In turn, the difluoroacetyl radical is expected to react with the neighboring ligands, such as methacrylate ones. Reoxidation of Zn-sites after ligand loss could occur after the exposed sample is exposed to air, as indicated by the XPS studies.

\section{Conclusions}

The $\mathrm{Zn}$ (MA)(TFA) compound has shown the potential to be a competitive material for EUVL applications. EUV interference lithography tests on the $\mathrm{Zn}(\mathrm{MA})(\mathrm{TFA})$ resist showed that targeted half-pitch of line/space features for $50 \mathrm{~nm}, 40 \mathrm{~nm}, 30 \mathrm{~nm}$ and $22 \mathrm{~nm}$ can be patterned with a dose of $\sim 20 \mathrm{~mJ} \mathrm{~cm}^{-2}$ and unbiased LWR values that comply with the industry requirements. From spectroscopic studies combining FTIR, UV-vis absorption and XPS, we propose a plausible mechanism behind the high sensitivity of this resist that consists of three major reaction paths.
One path starts with the ionization and decarboxylation of either the methacrylate or trifluoroacetate ligand to give rise to radical species that can initiate the oligomerization of the terminal double bonds in neighbouring methacrylate ligands. The decarboxylated site, can evolve into hydroxo and oxo species that could bridge neighbouring clusters. Along with these reactions, XPS studies suggest that a third path involves the migration of fluorine atoms from the organic shell to the metal core, most likely promoted by electron attachment. These novel insights into the reaction mechanisms and their correlation to the lithography performance of $\mathrm{Zn}(\mathrm{MA})(\mathrm{TFA})$ will help the EUV lithography community to have a better understanding of the molecular design required for new efficient EUV resist materials.

\section{Conflicts of interest}

There are no conflicts to declare.

\section{Acknowledgements}

The authors acknowledge the contribution of Najmeh Sadegh for her help with the implementation of the LWR analysis. The research leading to these results has received funding from the European Community's Seventh Framework Programme (FP7/2007-2013) under grant agreement no. 312284 (CALIPSO, 20180993). This work has been carried out within ARCNL, a public-private partnership between University of Amsterdam (UvA), Vrije Universiteit Amsterdam (VU), the Netherlands Organization for Scientific Research (NWO), and ASML.

\section{References}

1 C. Wagner and N. Harned, Nat. Photonics, 2010, 4, 24.

2 C. A. Mack, IEEE Trans. Semicond. Manuf., 2011, 24, 202-207.

3 R. M. M. Hasan and X. Luo, Nanomanuf. Metrol., 2018, 1, 67-81.

4 A. Lio, Proc. SPIE, 2016, 9776, 97760V. 
5 M. Neisser, J. Microelectron. Manuf., 2018, 1, 1-8.

6 A. Lio, Synchrotron Radiat. News, 2019, 32, 9-14.

7 O. Kostko, B. Xu, M. Ahmed, D. S. Slaughter, D. F. Ogletree, K. D. Closser, D. G. Prendergast, P. Naulleau, D. L. Olynick and P. D. Ashby, J. Chem. Phys., 2018, 149, 154305.

8 P. D. Ashby, D. L. Olynick, D. F. Ogletree and P. P. Naulleau, Adv. Mater., 2015, 27, 5813-5819.

9 A. Narasimhan, S. Grzeskowiak, B. Srivats, H. C. Herbol, L. Wisehart, C. Kelly, W. Earley, L. E. Ocola, M. Neisser and G. Denbeaux, Proc. SPIE, 2015, 9422, 942208.

10 A. Narasimhan, L. Wisehart, S. Grzeskowiak, L. E. Ocola, G. Denbeaux and R. L. Brainard, J. Photopolym. Sci. Technol., 2017, 30, 113-120.

11 EUV Lithography, ed. V. Bakshi, SPIE Press, 2018.

12 O. Yildirim, E. Buitrago, R. Hoefnagels, M. Meeuwissen, S. Wuister, G. Rispens, A. van Oosten, P. Derks, J. Finders and M. Vockenhuber, Proc. SPIE, 2017, 10143, 101430Q.

13 D. De Simone, P. Vanelderen and G. Vandenberghe, J. Photopolym. Sci. Technol., 2017, 30, 613-617.

14 R. Fallica, J. Haitjema, L. Wu, S. C. Ortega, A. M. Brouwer and Y. Ekinci, J. Micro/Nanolithogr., MEMS, MOEMS, 2018, 17, 23505.

15 L. Li, X. Liu, S. Pal, S. Wang, C. K. Ober and E. P. Giannelis, Chem. Soc. Rev., 2017, 46, 4855-4866.

16 C. Luo, C. Xu, L. Lv, H. Li, X. Huang and W. Liu, RSC Adv., 2020, 10, 8385-8395.

17 X. Wang, Z. Tasdemir, I. Mochi, M. Vockenhuber, L. van Lent-Protasova, M. Meeuwissen, R. Custers, G. Rispens, R. Hoefnagels and Y. Ekinci, Proc. SPIE, 2019, 10957, 109570A.

18 M. Trikeriotis, M. Krysaki, Y. S. Chung, C. Ouyang, B. Cardineau, R. Brainard, C. K. Ober, E. P. Giannelis and K. Cho, J. Photopolym. Sci. Technol., 2012, 25, 583-586.

19 M. E. Krysak, J. M. Blackwell, S. E. Putna, M. J. Leeson, T. R. Younkin, S. Harlson, K. Frasure and F. Gstrein, Proc. SPIE, 2014, 9048, 904805.

20 R. Del, Re, J. Passarelli, M. Sortland, B. Cardineau, Y. Ekinci, E. Buitrago, M. Neisser, D. A. Freedman and R. L. Brainard, J. Micro/Nanolithogr., MEMS, MOEMS, 2015, 14, 43506.

21 H. Xu, K. Sakai, K. Kasahara, V. Kosma, K. Yang, H. C. Herbol, J. Odent, P. Clancy, E. P. Giannelis and C. K. Ober, Chem. Mater., 2018, 30, 4124-4133.

22 B. Cardineau, R. Del Re, H. Al-Mashat, M. Marnell, M. Vockenhuber, Y. Ekinci, C. Sarma, M. Neisser, D. A. Freedman and R. L. Brainard, Proc. SPIE, 2014, 9051, 90511B.

23 L. Wu, M. Vockenhuber, Y. Ekinci and S. Castellanos, Proc. SPIE, 2019, 10957, 109570B.

24 E. C. Mattson, Y. Cabrera, S. M. Rupich, Y. Wang, K. A. Oyekan, T. J. Mustard, M. D. Halls, H. A. Bechtel, M. C. Martin and Y. J. Chabal, Chem. Mater., 2018, 30, 6192-6206.

25 L. Wu, J. Liu, M. Vockenhuber, Y. Ekinci and S. Castellanos, Eur. J. Inorg. Chem., 2019, 4136-4141.

26 H. Xu, K. Sakai, K. Kasahara, V. Kosma, K. Yang, H. C. Herbol, J. Odent, P. Clancy, E. P. Giannelis and C. K. Ober, Chem. Mater., 2018, 30, 4124-4133.

27 A. De Silva, N. M. Felix and C. K. Ober, Adv. Mater., 2008, 20, 3355-3361.
28 H. Xu, V. Kosma, K. Sakai, E. P. Giannelis and C. K. Ober, J. Micro/Nanolithogr., MEMS, MOEMS, 2018, 18, 11007.

29 R. Maas, M.-C. van Lare, G. Rispens and S. F. Wuister, J. Micro/Nanolithogr., MEMS, MOEMS, 2018, 17, 41003.

30 L. Wu, M. Baljozovic, G. Portale, M. Vockenhuber, T. Jung, Y. Ekinci and S. Castellanos, J. Micro/Nanolithogr., MEMS, MOEMS, 2019, 18, 013504.

31 L. Wu, M. Tiekink, A. Giuliani, L. Nahon and S. Castellanos, J. Mater. Chem. C, 2019, 7, 33.

32 C. S. McCowan, T. L. Groy and M. T. Caudle, Inorg. Chem., 2002, 41, 1120-1127.

33 W. Clegg, D. R. Harbron, C. D. Homan, P. A. Hunt, I. R. Little and B. P. Straughan, Inorganica Chim. Acta, 1991, 186, 51-60.

34 R. M. Gordon and H. B. Silver, Can. J. Chem., 1983, 61, 1218-1221.

35 P. Cubillas, K. Etherington, M. W. Anderson and M. P. Attfield, CrystEngComm, 2014, 16, 9834-9841.

36 S. B. Ötvös, O. Berkesi, T. Körtvélyesi and I. Pálinkó, Inorg. Chem., 2010, 49, 4620-4625.

37 N. L. Rosi, J. Eckert, M. Eddaoudi, D. T. Vodak, J. Kim, M. O'Keeffe and O. M. Yaghi, Science, 2003, 300, 1127-1129.

38 M. D. Christianson, M. M. Meyer, O. Ongayi, D. Valeri and M. Wagner, Proc. SPIE, 2013, 8682, 868216.

39 M. Carraro and S. Gross, Materials, 2014, 7, 3956-3989.

40 I. Erukhimovich and M. O. de la Cruz, J. Polym. Sci., Part B: Polym. Phys., 2004, 45, 2215-2231.

41 U. Schubert, Chem. Soc. Rev., 2011, 40, 575-582.

42 U. Schubert, Chem. Mater., 2001, 13, 3487-3494.

43 N. Thakur, L.-T. Tseng, M. Vockenhuber, Y. Ekinci and S. Castellanos, J. Micro/Nanolithogr., MEMS, MOEMS, 2019, 18, 43504.

44 N. Mojarad, J. Gobrecht and Y. Ekinci, Microelectron. Eng., 2015, 143, 55-63.

45 N. Mojarad, D. Fan, J. Gobrecht and Y. Ekinci, Opt. Lett., 2014, 39, 2286-2289.

46 G. F. Lorusso, T. Sutani, V. Rutigliani, F. Van Roey, A. Moussa, A.-L. Charley, C. Mack, P. Naulleau, C. Perera and V. Constantoudis, J. Micro/Nanolithogr., MEMS, MOEMS, 2018, 17, 41009.

47 G. Palasantzas, Phys. Rev. B: Condens. Matter Mater. Phys., 1993, 48, 14472-14478.

48 I. Mochi and Y. Ekinci, Synchrotron Radiat. News, 2019, 32, 22-27.

49 C. Mack, Fundamental Principles of Optical Lithography: The Science of Microfabrication, John Wiley \& Sons, 2008.

50 A. Grenville, J. T. Anderson, B. L. Clark, P. De Schepper, J. Edson, M. Greer, K. Jiang, M. Kocsis, S. T. Meyers, J. K. Stowers, A. J. Telecky, D. De Simone and G. Vandenberghe, Proc. SPIE, 2015, 9425, 94250S.

51 B. Cardineau, R. Del Re, M. Marnell, H. Al-Mashat, M. Vockenhuber, Y. Ekinci, C. Sarma, D. A. Freedman and R. L. Brainard, Microelectron. Eng., 2014, 127, 44-50.

52 J. Haitjema, Y. Zhang, M. Vockenhuber, D. Kazazis, Y. Ekinci and A. M. Brouwer, J. Micro/Nanolithogr., MEMS, MOEMS, 2017, 16, 033510. 
53 T. Gädda, L. N. Dang, M. Laukkanen, K. Karaste, O. Kähkönen, E. Kauppi, D. Kazazis, Y. Ekinci and J. T. Rantala, Proc. SPIE, 2019, 10960, 109600B.

54 R. Chen, Y. Li, L. Tang, H. Yang, Z. Lu, J. Wang, L. Liu and K. Takahashi, RSC Adv., 2017, 7, 40020-40027.

55 M. Sportelli, M. Valentini, R. Picca, A. Milella, A. Nacci, A. Valentini and N. Cioffi, Appl. Sci., 2018, 8, 77.

56 Y. Kawamoto, K. Ogura, M. Shojiya, M. Takahashi and K. Kadono, J. Fluorine Chem., 1999, 96, 135-139.

57 E. Polydorou, A. Zeniou, D. Tsikritzis, A. Soultati, I. Sakellis, S. Gardelis, T. A. Papadopoulos, J. Briscoe, L. C. Palilis and S. Kennou, J. Mater. Chem. A, 2016, 4, 11844-11858.

58 S. G. Rosenberg, M. Barclay and D. H. Fairbrother, ACS Appl. Mater. Interfaces, 2014, 6, 8590-8601.

59 L. Wu, M. Tiekink, A. Giuliani, L. Nahon and S. Castellanos, J. Mater. Chem. C, 2019, 7, 33-37.

60 K. Ahlenhoff, S. Koch, D. Emmrich, R. Dalpke, A. Gölzhäuser and P. Swiderek, Phys. Chem. Chem. Phys., 2019, 21, 2351-2364.
61 F. Lebreux, F. Buzzo and I. Marko, ECS Trans., 2008, 13, 1-10. 62 C.-C. Yeh, H.-C. Liu, W. Heni, D. Berling, H.-W. Zan and O. Soppera, J. Mater. Chem. C, 2017, 5, 2611-2619.

63 F. Stehlin, F. Wieder, A. Spangenberg, J.-M. Le Meins and O. Soppera, J. Mater. Chem. C, 2014, 2, 277-285.

64 L. Li, S. Chakrabarty, K. Spyrou, C. K. Ober and E. P. Giannelis, Chem. Mater., 2015, 27, 5027-5031.

65 M. Zawadzki, A. Chachereau, J. Kočišek, C. M. Franck and J. Fedor, J. Chem. Phys., 2018, 149, 204305.

66 J. P. Wiens, J. C. Sawyer, T. M. Miller, N. S. Shuman, A. A. Viggiano, M. Khamesian, V. Kokoouline and I. I. Fabrikant, Phys. Rev. A: At., Mol., Opt. Phys., 2016, 93, 32706.

67 J. Langer, M. Stano, S. Gohlke, V. Foltin, S. Matejcik and E. Illenberger, Chem. Phys. Lett., 2006, 419, 228-232.

68 M. Orzol, T. Sedlacko, R. Balog, J. Langer, G. P. Karwasz, E. Illenberger, A. Lafosse, M. Bertin, A. Domaracka and R. Azria, Int. J. Mass Spectrom., 2006, 254, 63-69.

69 E. Böhler, J. Warneke and P. Swiderek, Chem. Soc. Rev., 2013, 42, 9219-9231. 